\title{
Change in Angle of Eyes with Primary Angle Closure Suspects One Year after Laser Peripheral Iridotomy : a randomised study
}

\section{Dapeng Mou}

Beijing Tongren Hospital https://orcid.org/0000-0001-9846-6025

\section{Yuan Bo Liang}

Beijing Tongren Hospital

Su Jie Fan

Handan eye hospital

Yi Peng

Beijing Tongren Hospital

Ning Li Wang ( $\nabla$ nlwang66@sina.com )

https://orcid.org/0000-0002-2538-8043

\section{Ravi Thomas}

university of Queensland

\section{Research article}

Keywords: Primary Angle Closure Suspects(PACS), anterior chamber angle, Laser Peripheral Iridotomy(LPI), Intraocular Pressure (IOP)

Posted Date: August 15th, 2019

DOI: https://doi.org/10.21203/rs.2.12953/v1

License: (c) (1) This work is licensed under a Creative Commons Attribution 4.0 International License. Read Full License 


\section{Abstract}

Background: To report the changes in anterior chamber angle and progression rate to PAC(primary angle closure) following laser peripheral iridotomy (LPI) in primary angle closure suspects(PACS). Methods: Prospective, randomized controlled interventional clinical trial conducted at the Handan Eye Hospital, China. 134 bilateral PACS, defined as non-visibility of the posterior trabecular meshwork for $\geq 180$ degrees on gonioscopy were randomly assigned to undergo LPI in one eye. Gonioscopy and Goldmann applanation tonometry were performed prior to, on day 7 and 12 months' post LPI. Results: 80 of 134 patients $(59.7 \%$ ) could be followed up at one year. The mean IOP in treated eyes was $15.9 \pm 2.7 \mathrm{mmHg}$ at baseline, $15.4 \pm 3.0 \mathrm{mmHg}$ on day $7 ; 16.5 \pm 2.9 \mathrm{mmHg}$ at one month and $15.5 \pm 2.9 \mathrm{mmHg}$ at 12 months; the IOP in untreated eyes was similar $(\mathrm{p}=0.834)$. One or more quadrants of the angle opened in $93.7 \%$ of the LPI treated eyes, but $67.0 \%$ (53/79) remained closed in two or more quadrants. The progression rate to PAC in untreated eyes was $3.75 \%$ and one developed acute angle closure glaucoma(AACG), the progression rate to PAC(primary angle closure) in treated eyes $2.5 \%$ in treated eyes, none had developed PAS or AACG. Conclusion: LPI can open some of the occludable angle in the majority of eyes with PACS, but $67 \%$ continue to have non-visibility of the trabecular meshwork for over 180 degrees. IOP remained similar in treated and untreated eyes. Further research is needed to determine the full implications of residual closure as well as the need for follow up and treatment in PACS. The cumulative incidence for PAC/AACG in treated eyes were not significantly different from untreated eyes. Trial registration: Current Controlled Trials Chinese Clinical Trial Registry ChiCTR-TCH-10000820, as well as the date of registration(retrospectively registered).

\section{Background}

The prevalence of PACG is highest in Asia, it has been estimated that $87 \%$ of those blinded by primary angle-closure glaucoma (PACG) live in Asia, by 2020, China will be home to half of the patients with PACG [1-5]. LPI is the current standard of care in PACG [6-8], prevents acute angle closure glaucoma (AACG) and decreases risk of such acute attacks in fellow eyes [9-13].

However, there are approximately 28.2 million PACS in China and the role of LPI in their management is less clear [14,15].

A knowledge of the natural history of PACS and the effect of LPI would help in public health strategy as well as individual management decisions [16]. In a 6 year community based follow up study in urban China, Ye et al. reported that 4.1\% (20/485) PACS [defined as less anterior chamber depth (ACD $\leq 2.0 \mathrm{~mm}$, or limbal $A C D \leq 1 / 4$ corneal thickness(CT); or Iris light band ratio $\leq 1 / 4$ with oblique flashlight test), developed PAC or PACG [17]. In a population-based Indian cohort that used gonioscopy for the definition, $22 \%$ of PACS progressed to PAC and $28 \%$ of PAC progressed to PACG over 5 years;none of the PACS developed PACG in the 5 years of follow up[18]. 
The results of LPI in PACS are variably reported. In a retrospective hospital based case series, LPI controlled IOP over 5 years in 16/18 (90\%) Chinese eyes with PACS [19]. In a two-year hospital based follow up study none of 27 eyes with PACS undergoing LPI progressed to PAC or PACG [20]. However, a population-based clinical trial reported that $6.7 \%$ of PACS in Mongolia progressed to PAC after LPI in 6 years [21].

Considering the large number of PACS in China and the potential significance of angle closure as a public health problem, we conducted a randomized trial, the aim of the present study was to investigate the efficacy of LPI in PACS in one eye and chart the course of untreated fellow eyes. Herein we report the one year results of IOP and angle changes in this trial. Our study adheres to CONSORT guidelines.

\section{Methods}

\section{Participant and study design}

The study was approved by the ethics committee of the Tongren Eye Centre, Capital Medical University, and the ethics committee of Handan Eye Hospital and conducted in accordance with the tenets of the Declaration of Helsinki at the department of ophthalmology in Handan 3rd Hospital (a branch of the clinical research center of Beijing Tongren Eye Center), Hebei Province, China. The trial was registered at the Chinese clinical trial registry center (see: http://www.chictr.org.cn/showproj.aspx?proj = 8716, ChiCTR$\mathrm{TCH}-10000820$ ). All participants provided an informed consent.

Patients were consecutively recruited from the glaucoma clinic of the Handan Eye Hospital, between October, 2005 and January, 2008,all eligible subjects have one year follow up.All subjects underwent a routine ophthalmic examination including best corrected visual acuity using a Log Mar chart (Precision Vision, La Salle, IL, USA), refraction, slit-lamp examination, gonoiscopy (FSJ), optic disc assessment with direct ophthalmoscope (FSJ) and visual field test using the 24-2-Swedish Interactive Testing Algorithm (SITA) fast program with Humphrey Visual Field Analyzer 750i (Carl Zeiss, Jena, Germany).

PACS was defined as non-visibility of the filtering trabecular meshwork for $\geq 180$ degrees on an "over the hill" view on gonioscopy (one mirror Goldman lens in dim illumination), without PAS and no clinically evident glaucomatous optic damage or visual field change [22,23].

Inclusion criteria for this study included:(1) Age $\geq 40$ years; (2) non-visibility of the trabecular meshwork for $\geq 180^{\circ}$ in both eyes; (3) No PAS; (4) IOP $\leq 21 \mathrm{mmHg}$ without any IOP lowering medications; (5) normal optic disc appearance (cup:disc ratio $<0.7$, rim:disc ratio $>0.1$ and (6) normal visual field (VF) determined by a normal glaucoma hemifield test.

Patients with any of the following conditions were excluded: (1) Severe systemic disease such as heart, renal failure; which could preclude eye examinations and follow up. (2) Any past ocular surgery. (3) History or signs of acute angle closure attack. (4) Need for frequent pupil dilation due to diabetes or other retinal disease; (5) Plan to move out of Handan city within 5 years (6) Unwillingness to sign an informed 
consent (7) Those considered at high risk of acute angle-closure glaucoma (an arbitrary IOP increase of $\geq 15 \mathrm{mmHg}$ following mydriasis or darkroom provocative testing).

An incident event of AACG or PAC was the primary outcome. AACG was characterized by a combination of acute symptoms of pain, headache, blurred vision and haloes around lights with signs of ischemic iris changes, corneal edema, glaucomflecken, and elevated IOP above $30 \mathrm{mmHg}$. PAC was defined as PACS with IOP $>21 \mathrm{mmHg}$ on two separate occasions and / or peripheral anterior synechia of 0.5 clock hours.

Goldmann applanation tonometry was performed by a certified clinical nurse prior to LPI and on day 7 , one month and 12 months post LPI. At each visit, the mean of 3 readings was recorded.

Gonioscopy was carried out by one glaucoma specialist (FSJ) who was blinded after assignment to the treatment prior to LPI, day 7, one month and 12 months post LPI, using a Goldmann-type 1-mirror lens with low-ambient illumination that did not impinge on the pupil. This was followed by dynamic gonioscopy using the same lens to confirm the absence of peripheral anterior synechia (PAS). The interobserver reproducibility for gonioscopy between FSJ and another glaucoma specialist for detection of occludable angles (yes/no) was determined to be good (kappa $=0.67$ ); that for clock hours of PAS was perfect [Intraclass correlation $($ ICC $)=0.972$ ]

\section{Randomization and Allocation Concealment.}

The SPSS program generated a series of numbers to randomly select the right or left eye of the participants to be treated with LPI. Allocation concealment was achieved by involving a research nurse(ZXY) in the process: when a patient met the criteria for enrollment, the ophthalmologist(FSJ) involved in this study contacted the research nurse who communicated the allocation.

\section{Interventions}

This study followed routine clinical practice. LPI was performed with an Abraham contact lens in the superior (10:00 to 2:00 o'clock) region of the iris by FSJ or LYB using a Nd:YAG laser (YL-1600; NIDEK Co., LTD, Japan).

$1 \%$ pilocarpine eye drops (Freda Company, Shandong, China) were instilled 4 times at an interval of 5 minutes prior to treatment. The laser power was initially set at 4-mJ and increased as necessary (up to 11 $\mathrm{mJ}$ ) until a patent iridotomy of approximately $0.2 \mathrm{~mm}$ was achieved. Full-thickness perforation was confirmed by dispersion of pigment with flow of aqueous from the posterior to the anterior chamber and direct visualization of the posterior chamber.

If the IOP measured 1 hour after iridotomy was $\geq 30 \mathrm{mmHg}$ oral acetazolamide $(250 \mathrm{mg})$ was given. Due to non-availability of plain steroid drops, the eye undergoing LPI eye was treated with Tobradex eye drops (Alcon Laboratories, Fort Worth, TX囚four times daily for 3 days. 


\section{Sample size estimation}

Based on an expected $22 \%$ incidence of PAC in control PACS and reduction to $5 \%$ with $\mathrm{LP}^{22}$, a sample size of 116 patients was calculated to allow demonstration of superiority at the $5.0 \%$ significance level with a power of $80 \%$. Anticipating a loss to follow up of $10 \%$ per year, the sample size was increased to 177. Enrollment was slow and 134 eligible subjects were recruited between October 2005 and January 2008.

\section{Statistical Analysis}

All analyses were performed using SAS 9.0.3 statistical software (SAS Inc., Chicago, IL). Data from the 1year visit were used for analysis.

A paired t-test was used to compare the change in VA (LogMAR), IOP, Spherical equivalent (SE), anterior chamber depth (ACD), lens thickness (LT) and axial length (AXL) in the treated eye to that in the untreated fellow eye. We used a general linear model to test the difference in IOP with repeated measurements. The means and standard deviations (SD) were calculated for continuous outcome variables with a normal distribution. Statistical significance was determined using the Student's t-test (normal distribution) or rank-sum test (non-normal distribution). To compare the incidence rate of PAC/AACG between treated eyes and untreated eyes, we used Fisher exact test (1-sided). $\mathrm{P}<0.05$ was considered to be statistically significant.

\section{Results}

\section{Characteristics of the participants}

191 subjects were eligible for the study. 12 patients who declined to participate and 45 who refused randomization were excluded. 134 patients were followed up for one year and one eye was treated with $\mathrm{LPI}$ at random. 10 subjects were lost to follow up on day 7, 23 subjects were lost to follow up at one month and 54 subjects ( 8 patients declined follow up, 25 could not be contacted, 2 patients moved and could not be contacted and 19 did not attend follow up despite repeated requests) were lost to follow up at 1 year $\bigotimes$ Figure $1 \rrbracket$. The mean age of the treated participants was $60.5 \pm 8.0$ years and $87 \%$ were female (117/134). 80 (58.9\%) attended the one year follow up. 26 of the 134 patients who could not attend the follow up were contacted by telephone and none of them had experienced symptoms of AACG.

The baseline characteristics and the quadrants of non-visible trabecular meshwork in the treated eyes was not significantly different from the fellow eye (Table 1). Since the drop off rate was high, we compared the baseline characteristics between the those who attended follow up and those who did not attend follow up: there was no significant difference in age, gender, ocular parameters or quadrants of 
non-visible meshwork. The IOP in the participants who missed the 1-year follow-up was a little lower, and they had better VA than the participants who attended (Table 2).

\section{IOP outcomes}

The mean IOP in the treated eyes was $15.9 \pm 2.7 \mathrm{mmHg}$ at baseline, $15.4 \pm 3.0 \mathrm{mmHg}$ on day $7 ; 16.5 \pm 2.9$ $\mathrm{mmHg}$ at one month and $15.5 \pm 2.9 \mathrm{mmHg}$ at 12 months. The change in IOP between the baseline and follow up visits were very similar in the treated eyes and the untreated fellow eyes at all follow up visits (Figure 2). IOP in eyes with four, three and two quadrants of non-visible trabecular meshwork pre operatively decreased by $0.82 \pm 3.3 \mathrm{mmHg}, 0.14 \pm 3.4 \mathrm{mmHg}$ and $1.6 \pm 3.5 \mathrm{mmHg}$ respectively. There was no difference between treated and untreated eyes $(p=0.440 \sim 0.612)$.

\section{Gonioscopy outcomes}

79 patients underwent gonioscopy at the 12 month visit. Five of the untreated eyes (6\%) showed one quadrant of increase in "closure" but none developed PAS (Table 3). 13 treated eyes (16.5\%) had a completely open angle, 74 (93.7\%) had opened by at least one quadrant and in $67.0 \%(53 / 79)$ the trabecular meshwork remained non-visible in two or more quadrants (Table 3).

\section{Progression rate to PAC outcomes}

Five of the 80 patients who attended the 1 year follow up had developed PAC or AACG. Those who progressed were females aged 49 to 69 years. Of the untreated eyes, one developed AACG while two eyes recorded an IOP $>21$ and were classified as PAC, the progression rate to PAC in untreated eyes was therefore $3.75 \%(95 \% \mathrm{Cl}, 0-7.9 \%)$. Two of the treated eyes had an IOP above $21 \mathrm{mmHg}$ and were classified as PAC $(2.5 \% ; 95 \% \mathrm{Cl}, 0-5.9 \%)$; none had developed PAS or AACG. The cumulative incidence for PAC/AACG in treated eyes were not significantly different from untreated eyes $(p=0.650)$.

\section{Discussion}

This randomized study found that at one year $3.75 \%$ of untreated PACS fellow eyes progressed to PAC / AACG; however, in this sample with a small number of events LPI did not significantly reduce the incidence of PAC. There was no significant reduction of IOP following LPI and 67.0\% (53/79) of treated eyes continued to have non visibility of trabecular meshwork in two or more quadrants.

The study confirms that the cause of angle closure, in this case in Chinese eyes, is multifactorial. The angle opened in at least one quadrants in $93.7 \%$ of the PACS eyes which is consistent with the reported role of pupillary block in angle closure disease among the Chinese population [24, 25]. However, following LPI about $2 / 3$ of the PACS eyes did not open in 2 or more quadrants; and $17.8 \%$ did not open in 3 
quadrants or more. This result is very similar to that of a population-based study from southern China in which about $19.4 \%$ still had 3 or more quadrants of non-visibility of meshwork following laser iridotomy [24]. Previous studies had reported that $37 \%$ to $60 \%$ of Chinese eyes undergoing LPI for early primary angle closure were still positive on the dark room prone provocative test [26, 27]. Non responsive cases may have some of the multiple mechanisms of angle-closure reported in Asian eyes [24, 25, 28-30].

Several studies have reported an association of IOP and angle width. Foster estimated a $0.2 \mathrm{~mm} \mathrm{Hg}$ increase per $10^{\circ}$ change in width in all four quadrants [31,32]. He et al reported a $3.1 \mathrm{mmHg}$ reduction in mean IOP at 2 weeks' post LPI [25], while Hisao et al observed a reduction of $2.3 \mathrm{mmHg}$ in mean IOP after LPI [33]. We did not observe significant IOP reduction following LPI at any of the follow up visits, did not find an association of IOP with the number of non-visible quadrants, and the change in IOP was similar to the fellow untreated eyes. In the present study, we found that at 7 days, one month and one year after LPI, mean IOP rise and fall in the treated and fellow untreated eyes almost simultaneously (Figure 2). Such effect seems to occur after trabeculectomy[34], Diestelhorst[32] studied the effect of trabeculectomy on the aqueous humour flow of the unoperated fellow eye, he concluded that filtration surgery in one eye triggers a CNS mediated, reflective increase in aqueous flow to maintain physiological stability in the anterior chamber of the surgically treated eye,we supposed that LPI may have the same effect as trabeculectomy.

The incidence of PAC/AACG in the untreated eyes in our study was $3.75 \%$, which was very similar to that reported in a population based Indian cohort $4.4 \%$ per year [22]. In Liwan study, approximately one in five people aged 50 years and older developed some form of angle closure over a 10-year period [36]. However, two of the LPI treated eyes also developed increased IOP without PAS in our study. All cases classified as progressing to PAC were based on recording an IOP $>21 \mathrm{mmHg}$. While a cut off is required for trial purposes, a single IOP recording could be erroneous and would not be considered clinically significant. While it is possible that indentation gonioscopy may have revealed differences in PAS between groups, it seems that any benefit of LPI at one year in preventing PAC is likely to be minimal, would not justify laser iridotomy for all and therefore cannot justify population based screening for PACS $[16,18,21,28,37-40]$. The sample size is small but if better follow up can be achieved, the planned 10 year follow up of the patients may provide more useful information.

The major limitation of our study is the loss to follow up of $40 \%$ at one year, much higher than expected; 26 of those who did not attend follow up were contacted by phone and confirmed absence any symptoms of AAC. In addition, all the participants lived within 100 kilometers of Handan Eye Hospital which is the only eye hospital for the region. As all subjects were informed and aware about the symptoms of angle-closure glaucoma and that free eye care would be available, it is unlikely that they had symptoms but did not attend. Also the baseline characteristics of patients who did or did not attend follow were similar for the treated eyes and the untreated eyes. Accordingly, we believe pathology if any, in subjects lost to follow up was likely to be PAC, not AACG. We are planning a home visit for all these patients for the ten-year visit. 
Another limitation is the subjective nature of gonioscopy for angle closure. Although the intraobserver agreement of gonioscopy for angle closure sounds good, in the untreated group one third of the cases had a wider angle comparing to the baseline, which probably represents variablility in goniosocpy. The changes in the angle were however different in treated compared to untreated eyes.

\section{Conclusions}

The present registry study indicated that $3.75 \%$ of untreated PACS fellow eyes progressed to PAC / AACG, a rate of progression similar to that reported in the literature[22]. The progression rate to PAC in LPI treated eyes was lower than untreated eyes.IOP was not reduced significantly after LPI and about two thirds of PACS continued to have two quadrants of non-visible trabecular meshwork, possibly due to nonpupillary block mechanisms of angle closure. The planned ten year follow up may help better clarify the role of LPI and the implications of residual closure on the need for follow up and treatment.

\section{Abbreviations}

PACS: primary angle closure suspect;PAC:primary angle closure, AACG: acute angle closure glaucoma; BCVA: Best-corrected visual acuity; LPI: laser peripheral iridotomy;IOP: intraocular pressure;PACG:primary angle closure glaucoma;CT: corneal thickness; IOP, SE: Spherical equivalent, ACD:anterior chamber depth, LT:Iens thickness; AXL: axial length $₫ S D$ : standard deviations; PAS: peripheral anterior synechia; ICC: Intraclass correlation

\section{Declarations}

\section{Acknowledgements}

The authors would like to thank all the employees who agreed to participate in this study and all the patients involved in this study for their support.

\section{Funding}

This article was supported in part by National "Eleventh Five-Year" Science and Technology Program. The Ministry of Science and Technology of the P. R. C. Grant No. 2007BAl18B08.

\section{Design of study}

P.Y and L. Y.B analyzed and interpreted the patient data. M. D. P., F. S. J., L. Y.B performed the patient examination, data collection and was a major contributor in writing the manuscript. All authors read and approved the final manuscript

\section{Competing interests}

The authors have no proprietary or commercial interest in any materials discussed in this article. 
The study was approved by the ethics committee of the Tongren Eye Centre, Capital Medical University, and the ethics committee of Handan Eye Hospital and conducted in accordance with the tenets of the Declaration of Helsinki at the department of ophthalmology in Handan 3rd Hospital (a branch of the clinical research center of Beijing Tongren Eye Center), Hebei Province, China. The trial was registered at the Chinese clinical trial registry center (http://www.chictr.org.cn/showproj.aspx?proj = 8716.ChiCTR$\mathrm{TCH}-10000820)$. Informed consent obtained from all study participants was written.

\section{Consent for publication}

Not applicable.

\section{Availability of data and materials}

The data that support the findings of this study are available upon request from the corresponding author [Wang]. The data are not publicly available due to containing information that could compromise the privacy of research participants. Data are available from the authors upon reasonable request and with permission of the Beijing Tongren hospital, China.

\section{Reference}

1.Quigley HA, Broman AT. The number of people with glaucoma worldwide in 2010 and 2020. The British journal of ophthalmology 2006; 90(3): 262-67.

2.Quigley HA. Number of people with glaucoma worldwide. The British journal of ophthalmology 1996; 80(5): 389-93.

3.Foster PJ, Johnson GJ. Glaucoma in China: how big is the problem? The British journal of ophthalmology 2001; 85(11): 1277-82.

4. Cheng JW, Zong Y, Zeng YY, Wei RL. The prevalence of primary angle closure glaucoma in adult Asians: a systematic review and meta-analysis. PLoS One 2014; 9 e103222.

5. Tham YC, Li X, Wong TY, Quigley HA, Aung T, Cheng CY. Global prevalence of glaucoma and projections of glaucoma burden through 2040: a systematic review and meta-analysis. Ophthalmology 2014; 121: 2081-90.

6.Saw SM, Gazzard G, Friedman DS. Interventions for angle-closure glaucoma: an evidence-based update. Ophthalmology 2003; 110(10): 1869-78; quiz 1878-1869, 1930.

7.Laser peripheral iridotomy for pupillary-block glaucoma. American Academy of Ophthalmology. Ophthalmology 1994; 101(10): 1749-58. 
8.Thomas R, Arun T, Muliyil J, George R. Outcome of laser peripheral iridotomy in chronic primary angle closure glaucoma. Ophthalmic surgery and lasers 1999; 30(7): 547-53.

9.Fleck BW, Dhillon B, Khanna V, Fairley E, McGlynn C. A randomised, prospective comparison of Nd:YAG laser iridotomy and operative peripheral iridectomy in fellow eyes. Eye (London, England) 1991; 5 ( Pt 3): 315-21.

10.Saunders DC. Acute closed-angle glaucoma and Nd-YAG laser iridotomy. The British journal of ophthalmology 1990; 74(9): 523-25.

11.Lowe RF. Primary angle-closure glaucoma. Prevention and early treatment. Israel journal of medical sciences 1972; 8(8): 1362-65.

12.Snow JT. Value of prophylactic peripheral iridectomy on the second eye in angle-closure glaucoma. Transactions of the ophthalmological societies of the United Kingdom 1977; 97(1): 189-191.

13. Moghimi S, Bijani F, Chen R, Yasseri M, He M, Lin SC, et al. Anterior segment dimensions following laser iridotomy in acute primary angle closure and fellow eyes[J]. American Journal of Ophthalmology, 2018;186:59-68. doi: 10.1016/j.ajo.2017.11.013.

14.Foster PJ, Johnson GJ. Glaucoma in China: how big is the problem? British Journal of Ophthalmology 2001; 85(11): 1277-82.

15.Friedman DS. Who needs an iridotomy? The British journal of ophthalmology 2001; 85(9): 1019-21.

16.Quigley HA, Congdon NG, Friedman DS. Glaucoma in China (and worldwide): changes in established thinking will decrease preventable blindness. Br J Ophthalmol 2001; 85(11): 1271-72.

17.Ye T, Yu Q, Peng S, Wang N, Chen X. [Six year follow-up of suspects of primary angle-closure glaucoma]. [Zhonghua yan ke za zhi] Chinese journal of ophthalmology 1998; 34(3): 167-9.

18. Thomas R, Sekhar GC, Parikh R. Primary angle closure glaucoma: a developing world perspective. Clin Experiment Ophthalmol 2007; 35(4): 374-8.

19.Bian AL, Zhao JL, Zhou Q, Zhang Y, Liu XL, Mao J. Long-term outcomes of laser peripheral iridectomy for primary angle closure glaucoma. [Zhonghua yan ke za zhi] Chinese journal of ophthalmology 2009; 45(12): 1099-1104.

20.Pandav SS, Kaushik S, Jain R, Bansal R, Gupta A. Laser peripheral iridotomy across the spectrum of primary angle closure. Canadian journal of ophthalmology 2007; 42(2): 233-7.

21.Yip JL, Foster PJ, Uranchimeg D et al. Randomised controlled trial of screening and prophylactic treatment to prevent primary angle closure glaucoma. Br J Ophthalmol 2010;94(11):1472-7 
22.Thomas R, George R, Parikh R, Muliyil J, Jacob A. Five year risk of progression of primary angle closure suspects to primary angle closure: a population based study. $\mathrm{Br} \mathrm{J}$ Ophthalmol 2003; 87(4): 4504.

23.Thomas R, Parikh R, Muliyil J, Kumar RS. Five-year risk of progression of primary angle closure to primary angle closure glaucoma: a population-based study. Acta Ophthalmol Scand 2003; 81(5): 480-5.

24.He M, Friedman DS, Ge $\mathrm{J}$ et al. Laser peripheral iridotomy in eyes with narrow drainage angles: ultrasound biomicroscopy outcomes. The Liwan Eye Study. Ophthalmology 2007; 114(8): 1513-1519.

25.He M, Friedman DS, Ge J, Huang W, Jin C, Lee PS,et al. Laser peripheral iridotomy in primary angleclosure suspects: biometric and gonioscopic outcomes: the Liwan Eye Study. Ophthalmology 2007; 114(3): 494-500.

26.Wang NL, Zhou WB, Ye TC, Wu ZY, Liu H. The Clinical Study of Primary Angle Closure Glaucoma.. Zhonghua Yan Ke Za Zhi 1995;31(2):133-5 (In Chinese).

27. Hung PT, Chou LH. Provocation and mechanism of angle-closure glaucoma after iridectomy. Archives of ophthalmology 1979; 97(10): 1862-64.

28.Wang $\mathrm{N}, \mathrm{Wu} \mathrm{H}$, Fan Z. Primary angle closure glaucoma in Chinese and Western populations. Chinese medical journal 2002; 115(11): 1706-15.

29.Garudadri CS, Chelerkar V, Nutheti R. An ultrasound biomicroscopic study of the anterior segment in Indian eyes with primary angle-closure glaucoma. Journal of glaucoma 2002; 11(6): 502-7.

30.Wang N, Ouyang J, Zhou W, Lai M, Ye T, Zeng M,et al. [Multiple patterns of angle closure mechanisms in primary angle closure glaucoma in Chinese]. [Zhonghua yan ke za zhi] Chinese journal of ophthalmology 2000; 36(1): 46-51, 45, 46.

31.Foster PJ, Machin D, Wong TY, Ng TP, Kirwan JF, Johnson GJ, et al. Determinants of intraocular pressure and its association with glaucomatous optic neuropathy in Chinese Singaporeans: the Tanjong Pagar Study. Investigative ophthalmology \& visual science 2003; 44(9): 3885-91.

32. He M, Jiang Y, Huang S, Chang DS, Munoz B, Aung T, Foster PJ, et al. Laser peripheral iridotomy for the prevention of angle closure: a single-centre, randomised controlled trial.Lancet. 2019 Mar 13. pii: S01406736(18)32607-2. doi: 10.1016/S0140-6736(18)32607-2. [Epub ahead of print]

33.Hsiao CH, Hsu CT, Shen SC, Chen HS. Mid-term follow-up of Nd:YAG laser iridotomy in Asian eyes. Ophthalmic Surg Lasers Imaging 2003; 34(4): 291-98.

34.Vysniauskiene I, Shaarawy T, Flammer J, Haefliger IO.. Intraocular pressure changes in the contralateral eye after trabeculectomy with mitomycin C, Br J Ophthalmol 2005 89: 809-11 
35.Diestelhorst $\mathrm{M}$, Krieglstein $\mathrm{G}$. The effect of trabeculkectomy on the aqueous humor flow of the unoperated fellow eye. Graefes Arch Clin Exp Ophthalmol 1991;229:274-6.

36. Wang L, Huang W, Huang S, Zhang J, Guo X, Friedman DS, et al. Ten-year incidence of primary angle closure in elderly Chinese: The Liwan Eye Study[J]. British Journal of Ophthalmology, 2019;103(3):35560 .

37.Wang N, Zhou W, Ye T, Wu Z, Liu H. Clinical studies of primary angle closure glaucoma. [Zhonghua yan ke za zhi] Chinese journal of ophthalmology 1995; 31(2): 133-34.

38.Wang N, Wu Z, Liu H. Mechanism and etiology of primary chronic angle closure glaucoma. Yan ke xue bao 1994; 10(3): 186-92.

39.Lowe RF. A history of primary angle closure glaucoma. Survey of ophthalmology 1995; 40(2): 163-70.

40.Lowe RF. Clinical types of primary angle closure glaucoma. Australian and New Zealand journal of ophthalmology 1988; 16(3): 245-50.

\section{Tables}

Table 1. Baseline Characteristics of Treated and Untreated Fellow Eye of Primary Angle Closure Suspects

\begin{tabular}{|c|c|c|c|}
\hline \multirow[t]{2}{*}{ Variable } & Treated Eye & Fellow Eye & \multirow[t]{2}{*}{$P$ value } \\
\hline & $(\mathrm{n}=134)$ & $(n=134)$ & \\
\hline $\mathrm{IOP}(\mathrm{mmHg})$ & $15.9 \pm 2.6$ & $15.9 \pm 2.8$ & $.912^{*}$ \\
\hline Quadrants of & $3.5 \pm 0.7$ & $3.6 \pm 0.6$ & $.577 *$ \\
\hline \multicolumn{4}{|c|}{ occludable angle } \\
\hline BCVA & $0.1 \pm 0.1$ & $0.1 \pm 0.2$ & $0.130 * *$ \\
\hline SE & $1.0 \pm 1.4$ & $1.1 \pm 1.3$ & $.210^{*}$ \\
\hline $\mathrm{ACD}(\mathrm{mm})$ & $2.5 \pm 0.3$ & $2.5 \pm 0.2$ & $.260^{*}$ \\
\hline $\mathrm{LT}(\mathrm{mm})$ & $4.7 \pm 0.3$ & $4.7 \pm 0.4$ & $.080^{*}$ \\
\hline $\mathrm{AXL}(\mathrm{mm})$ & $22.2 \pm 0.8$ & $22.1 \pm 1.1$ & $.511^{*}$ \\
\hline
\end{tabular}

IOP: intraocular pressure

BCVA: Best-corrected visual acuity (Logmar)

SE: Spherical equivalence

ACD: anterior chamber depth

LT: lens thickness

AXL: axial length

*paired-t test

** Wilcoxon Signed Ranks Test 
Table 2. Baseline Characteristics in Subjects who Attended or Missed 1-year Follow-up

\begin{tabular}{llll}
\hline Parameters & Attended Follow-up & Missed Follow-up & p value \\
\hline Female $\mathrm{n}(\%)$ & $\mathrm{n}=80$ & $\mathrm{n}=54$ & .131 \\
& $67(84 \%)$ & $50(93 \%)$ & \\
\hline Age (years) & & & .344
\end{tabular}

\begin{tabular}{llll}
\hline & \multicolumn{1}{c}{ Treated eyes } & & .039 \\
\hline BCVA* & $0.09 \pm 0.11$ & $0.14 \pm 0.13$ & .682 \\
\hline SE (diopters) & $0.9 \pm 1.5$ & $1.0 \pm 1.3$ & .014 \\
\hline IOP (mmHg) & $16.3 \pm 2.6$ & $15.2 \pm 2.6$ & .717 \\
& & & .950 \\
ACD (mm) & $2.5 \pm 0.2$ & $2.5 \pm 0.3$ & .605 \\
\hline LT (mm) & $4.7 \pm 0.3$ & $4.7 \pm 0.3$ & .981 \\
\hline AXL(mm) & & & $.92 .1 \pm 0.7$ \\
\end{tabular}

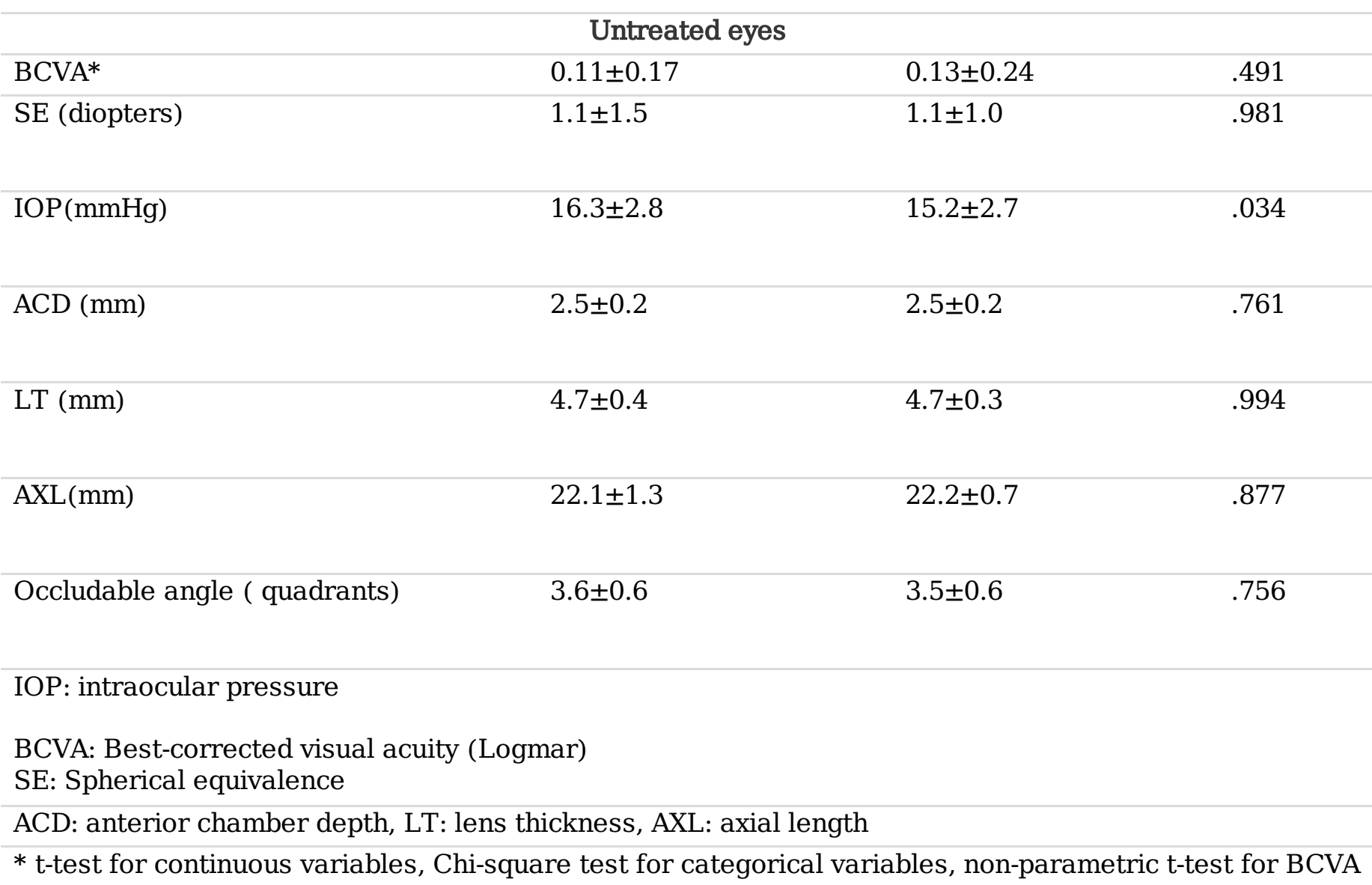


Table 3. The Number of Closed Quadrants (by static gonioscopy) at 1-Year and Baseline in Treated and Untreated Eyes

\begin{tabular}{|c|c|c|c|c|c|c|}
\hline \multirow{3}{*}{$\begin{array}{l}\text { Closed Angle } \\
\text { Before LPI }\end{array}$} & \multicolumn{5}{|c|}{ Treated Eyes } & \multirow[b]{3}{*}{ Total (\%) } \\
\hline & \multicolumn{5}{|c|}{ Closed Angle 1year After LPI (\%) } & \\
\hline & None & $\begin{array}{l}\text { One } \\
\text { quadrants }\end{array}$ & $\begin{array}{l}\text { Two } \\
\text { quadrants }\end{array}$ & $\begin{array}{l}\text { Three } \\
\text { quadrants }\end{array}$ & $\begin{array}{c}\text { Four } \\
\text { quadrants }\end{array}$ & \\
\hline \multirow[t]{2}{*}{ Two Quadrants } & 4( & $1(14.3)$ & $1(14.3)$ & $1(14.3)$ & $0(0.0)$ & 7( \\
\hline & $57.1)$ & & & & & 100.0) \\
\hline \multirow[t]{2}{*}{ Three Quadrants } & 6( & $6(27.3)$ & $8(36.4)$ & $2(9.1)$ & $0(0.0)$ & 22( \\
\hline & 27.3) & & & & & 100.0) \\
\hline \multirow[t]{2}{*}{ Four Quadrants } & $3(6.0)$ & $6(12.0)$ & $30(60.0)$ & $10(20.0)$ & $1(2.0)$ & 50( \\
\hline & & & & & & 100.0) \\
\hline \multirow[t]{3}{*}{ Total } & 13( & $13(16.5)$ & $39(49.4)$ & $13(16.5)$ & $1(1.3)$ & 79( \\
\hline & 16.5) & & & & & 100.0) \\
\hline & \multicolumn{5}{|c|}{ Untreated Eyes } & \\
\hline $\begin{array}{c}\text { Closed Angle at } \\
\text { Baseline }\end{array}$ & \multicolumn{5}{|c|}{ Closed Angle at $12^{\text {th }}$ month visit $\mathrm{n}(\%)$} & \\
\hline Two Quadrants & $0(0)$ & $1(16.7)$ & $4(66.7)$ & 1 (16.7) & $0(0)$ & $6(100.0)$ \\
\hline Three Quadrants & $1(4.8)$ & $1(4.8)$ & 5 (23.8) & $10(47.6)$ & $4(19.0)$ & $21(100.0)$ \\
\hline Four Quadrants & $2(3.8)$ & $0(0)$ & $6(11.5)$ & $13(25.0)$ & $31(59.6)$ & $52(100.0)$ \\
\hline Total & $3(3.8)$ & $2(2.5)$ & $15(19.0)$ & $24(30.4)$ & $35(44.3)$ & $79(100.0)$ \\
\hline
\end{tabular}

\section{Figures}




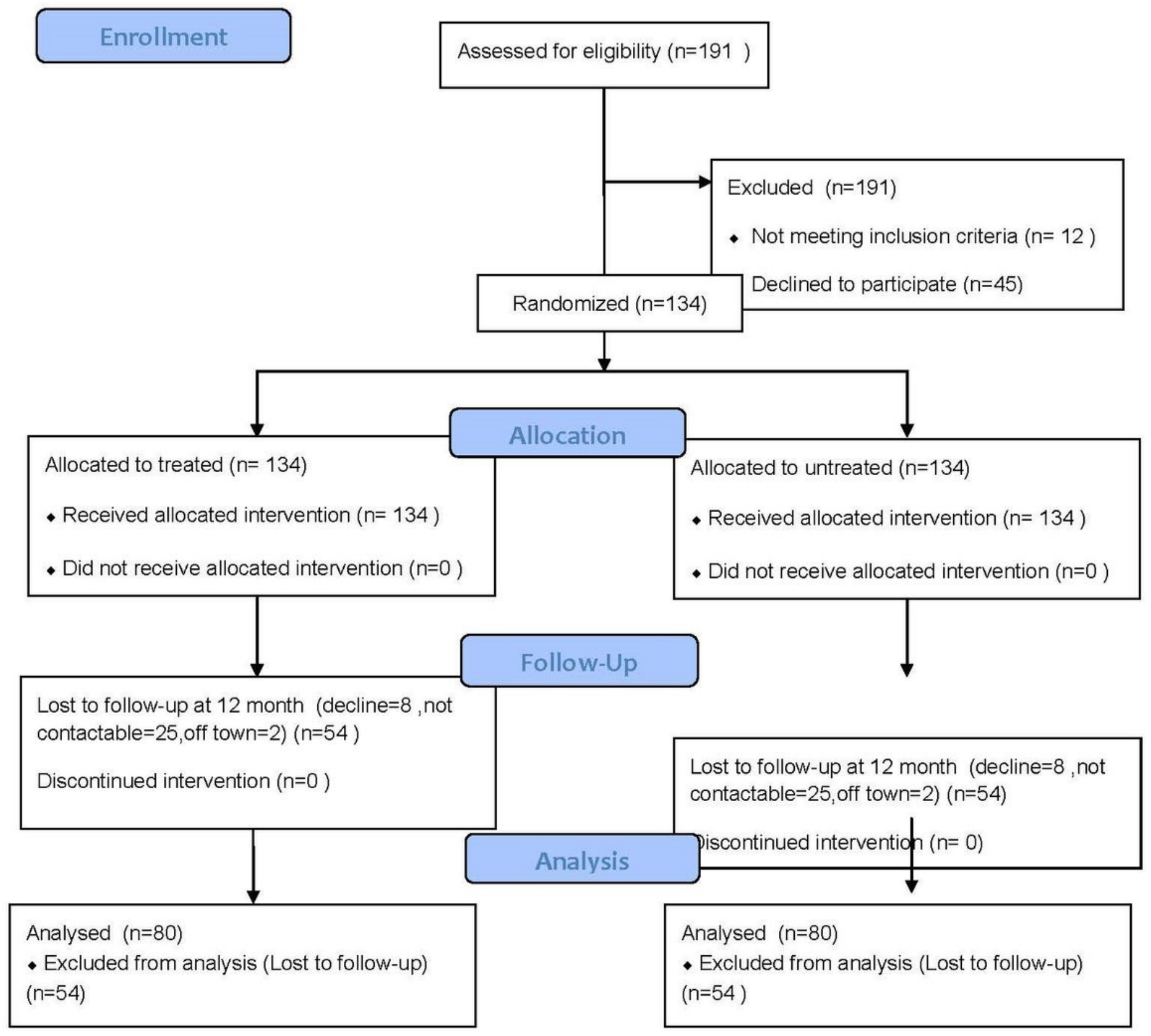

Figure 1

Flow chart of participants in the trail 


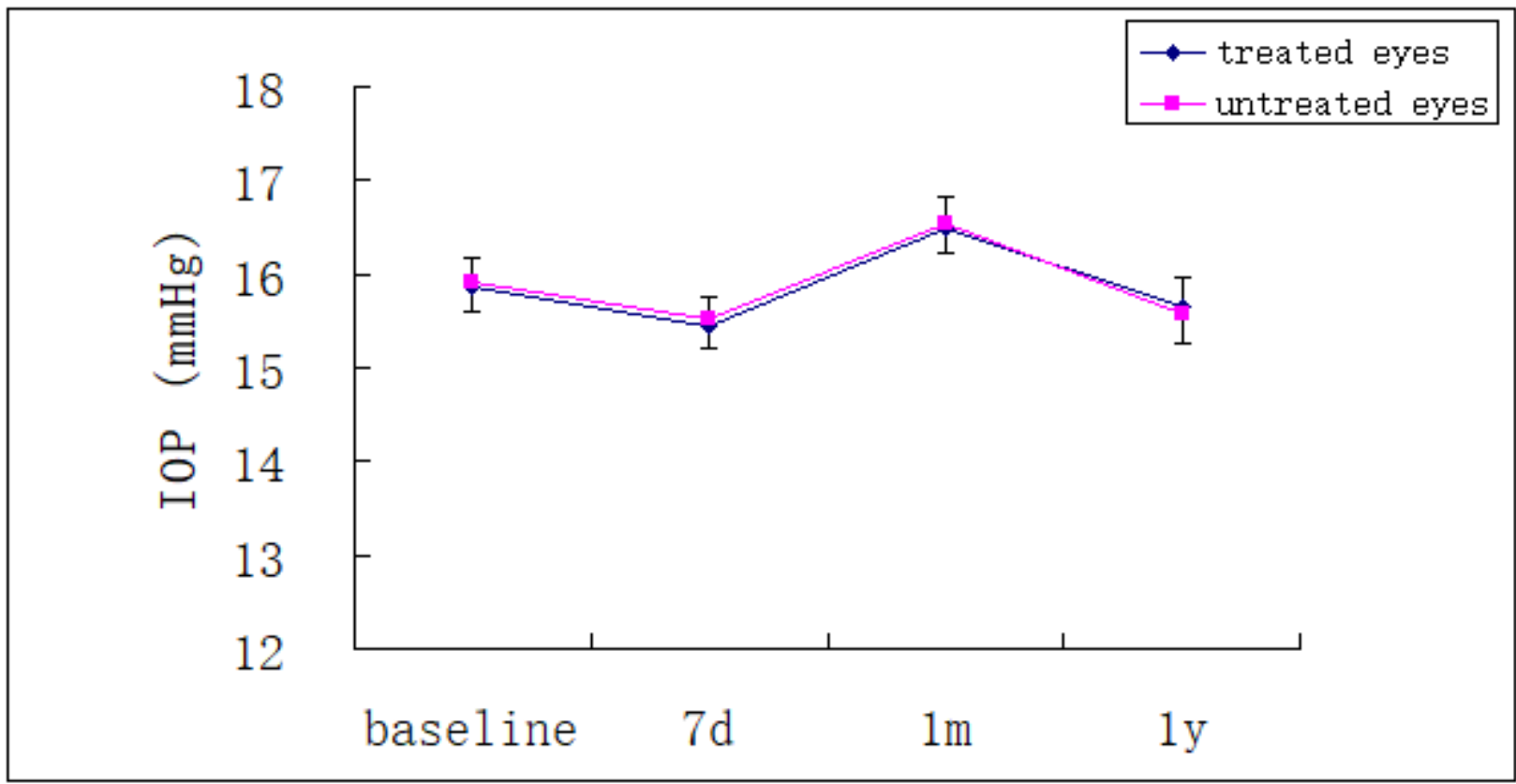

\section{Figure 2}

Intraocular Pressure (IOP) Changes Before and After Laser Peripheral Iridomoty in the Treated And Fellow Untreated Eye

\section{Supplementary Files}

This is a list of supplementary files associated with this preprint. Click to download.

- supplement1.doc 